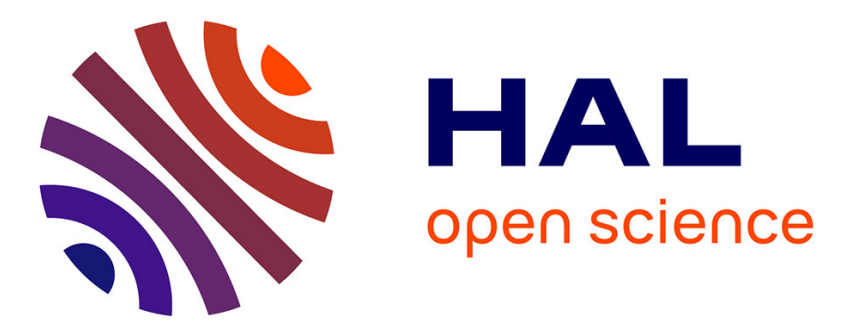

\title{
Bitcoin-specific fear sentiment and bitcoin returns in the COVID-19 outbreak
}

\author{
Ahmet Faruk Aysan, Ali Yavuz Polat, Hasan Tekin, Ahmet Semih Tunali
}

\section{To cite this version:}

Ahmet Faruk Aysan, Ali Yavuz Polat, Hasan Tekin, Ahmet Semih Tunali. Bitcoin-specific fear sentiment and bitcoin returns in the COVID-19 outbreak. 2021. hal-03354930

\author{
HAL Id: hal-03354930 \\ https://hal.science/hal-03354930
}

Preprint submitted on 26 Sep 2021

HAL is a multi-disciplinary open access archive for the deposit and dissemination of scientific research documents, whether they are published or not. The documents may come from teaching and research institutions in France or abroad, or from public or private research centers.
L'archive ouverte pluridisciplinaire HAL, est destinée au dépôt et à la diffusion de documents scientifiques de niveau recherche, publiés ou non, émanant des établissements d'enseignement et de recherche français ou étrangers, des laboratoires publics ou privés. 


\title{
Bitcoin-specific fear sentiment and bitcoin returns in the COVID- 19 outbreak
}

\author{
Ahmet Faruk Aysan \\ Hamad Bin Khalifa University, \\ Professor \& Program Coordinator, PhD in Islamic Finance and Economy \\ College of Islamic Studies, Qatar Foundation \\ aaysan@hbku.edu.qa \\ Ali Yavuz Polat \\ Abdullah Gul University, Kayseri, Turkey \\ Department of Economics \\ aliyavuz.polat@agu.edu.tr \\ ORCID: 0000-0001-5647-5310 \\ Hasan Tekin \\ Karabuk University, Karabuk, Turkey \\ hasantekin@karabuk.edu.tr \\ ORCID: 0000-0003-2855-215X \\ Ahmet Semih Tunali \\ Middle East Technical University, Ankara, Turkey \\ Department of Economics \\ tunali.ahmet@metu.edu.tr
}

\begin{abstract}
This study aims to investigate the effect of fear sentiment with a novel data set on Bitcoin's return, volatility and transaction volume. We divide the sample into two subperiods in order to capture the changing dynamics during the Covid-19 pandemic. We retrieve the novel fear sentiment data from Thomson Reuters MarketPsych Indices (TRMI). We denote the subperiods as pre- and post-COVID19 considering January 13th, 2020, when first Covid-19 confirmed case was reported outside China. We employ bivariate vector autoregressive (VAR) models given below with lag-length $\mathrm{k}$, to investigate the dynamics between Bitcoin variables and fear sentiment.Bitcoin market measures have dissimilar dynamics before and after the Coronavirus outbreak. The results reveal that due to the excessive uncertainty led by the outbreak, an increase in fear sentiment negatively affects the Bitcoin returns more persistently and significantly. For the post-COVID-19 period, an increase in fear also results in more fluctuations in transaction volume while its initial and cumulative effects are both negative. Due to extreme uncertainty caused by the COVID-19 pandemic, investors may trade more aggressively in the initial phases of the shock.
\end{abstract}

Keywords Bitcoin's return, COVID-19, fear sentiment, transaction volume, TRMI, volatility JEL Codes: C22, G12, G18, G41 


\section{Bitcoin-specific fear sentiment and bitcoin returns in the COVID- 19 outbreak}

\section{Introduction}

Bitcoin's price experienced a sharp drop, from 9147 USD on $6^{\text {th }}$ March 2020 to 4959 USD on $12^{\text {th }}$ March 2020 at the beginning of the Covid-19 pandemic, which proves that Bitcoin is affected by global events significantly. Then, later it increased to 61288 USD on $13^{\text {th }}$ March 2021, within a year ${ }^{1}$. Considering this high volatility in Bitcoin prices, it is insightful to analyze the effects of market sentiments on cryptocurrencies. This is even more relevant for Bitcoin since the sentiment drives the Bitcoin market in a laxer regulatory framework. COVID-19 as a natural experiment provides an opportunity to explore the pure effects of market sentiment on return, transaction volume and volatility of Bitcoin considering its decentralized and lightly regulated feature. This study allows us to infer lessons from markets in the absence of strict regulatory responses by the governments. Hence, investigating dynamics in the Bitcoin markets reveal more on the potential responses of markets under lighter government regulations ${ }^{2}$.

The behavioral literature focuses on analyzing the effects of the sentiments in markets (Tetlock 2007). However, the literature mostly employs generic sentiment measures that are often too general to capture asset-specific sentiments. For example, Da et al. (2015) and Chen et al. (2020) use generic market sentiment data derived from Google Trends that are not specific to the Bitcoin market. Existing research resorts to the general sentiment measures due to the availability of the data. However, in this paper, we benefit from a novel data set of Bitcoin-

\footnotetext{
${ }^{1}$ The price data is obtained from coinmetrics.io

${ }^{2}$ One may see some of the related works of the authors as follows in the references: Aysan, A. F. \& Bergigui, F. (2020), Aysan, A. F., Bergigui, F. \& Disli, M., (2021a), Aysan, A. F., Bergigui, F., \& Disli, M. (2021b), Aysan, A. F., Demirtaş, H. B. \& Saraç, M., (2021), Aysan, A. F., Disli, M., Nagayev, R., Rizkiah, S. K. \& Salim, K. (2021), Aysan, A. F., Khan, A. I. \& Topuz, H., (2021), Aysan, A. F., Khan, A. I., Topuz, H., \& Tunal1, A. S., (2021), and Aysan, A. F., Sadriu, B. \& Topuz, H., (2020).
} 
specific fear sentiment to capture the effects of market psychology on Bitcoin price, volume and price volatility.

There is a growing literature on Bitcoin market dynamics (Sahoo et al. 2019; Poyser 2019; Dahir et al. 2019; Kristoufek, 2019; Aloosh and Ouzan 2020) and whether Bitcoin acts as a safe haven (Aysan et al. 2019; Bouri et al. 2017, Guesmi et al. 2019; Shahzad et al. 2019) or whether it is a bubble (Cheah and Fry 2015; Geuder et al. 2019; Chaim and Laurini 2019). Previous research focused on the effects of sentiment on different market dynamics of Bitcoin (Karalevicius et al. 2017; Kalyvas et al. 2020). Shen et al. (2019) analyze the relationship between Bitcoin return and investor attention using the number of twitters as a proxy for investor attention. Da et al. (2015) construct a daily Internet search-based fear index and find that the fear index can predict asset prices and volatility.

There is no agreement yet whether BTC and other cryptocurrencies satisfy the three main properties of a money/currency (Bariviera et al. 2017, Baur et al. 2018). Thus, investors mostly treat cryptocurrencies as an asset rather than a currency. Baur et al. (2018) claim that: "Bitcoin is mainly used as a speculative investment" not "as an alternative currency". Corbet et al. (2018) analyze the relationship between the three known cryptocurrencies and conventional assets. They show that cryptocurrencies provide some diversification benefits in the short run. Zeng et al. (2020) investigate the connectedness between Bitcoin and other conventional assets and find that the relationship is limited implying a diversification opportunity. Regarding the regulatory difference between conventional assets and cryptocurrencies, Vandezande (2017) mentions that it is inevitable to understand crypto markets in relation to other conventional assets, in order to provide better insights for policy makers and regulators.

Earlier literature focuses on the effect of investor psychology and sentiment in the Bitcoin market (Kaminski 2014; Bukovina and Marticek 2016; Oad Rajput et al. 2020) and on the Covid-19 period (Demir et al. 2020; Conlon and McGee 2020; Chen et al. 2020), yet there are 
no studies investigating the impact of changing fear sentiment during Covid-19 outbreak on Bitcoin market dynamics. This study aims to analyze whether the Covid-19 pandemic, as an extreme shock, changed the dynamics in the Bitcoin market. More specifically, we check how fear sentiment affects Bitcoin variables before and after the pandemic and whether the effect of sentiment is more pronounced after the pandemic considering the unprecedented uncertainty during the Covid-19 period. We employ bivariate VAR models to investigate the relationship between the fear sentiment and Bitcoin's return, transaction volume and 30-day return volatility. Fear sentiment data provided by TRMI is a novel sentiment measure since it is unique to the Bitcoin market, not a generic sentiment measure.

The results reveal that due to the excessive uncertainty led by the COVID-19 outbreak, an increase in fear sentiment negatively affects the Bitcoin returns more persistently and significantly. For the post-COVID-19 period, an increase in fear also results in more fluctuations in transaction volume while its initial and cumulative effects are both negative. Due to extreme uncertainty caused by the COVID-19 pandemic, investors may trade more aggressively in the initial phases of the shock.

The paper has several main contributions. First, Chen et al. (2020) focus on the effects of the COVID-19 pandemic and report only VAR estimation results. Their analysis is not very informative since they cannot capture the dynamic relationship between variables due to not analyzing impulse response functions (IRFs). However, we analyze IRFs to understand the dynamic relationship between fear and our Bitcoin variables. Second, we use Bitcoin-specific fear sentiment data set of Thomson Reuters MarketPsych instead of more general market sentiment measures used in the literature and show that fear merges to have more permanent and volatile effects after the outbreak. This enables us to investigate the impact of investor psychology on Bitcoin market dynamics more accurately, since generic sentiment measures, as employed by the earlier literature, cannot capture market specific psychology. Next, this is the 
first study to examine the association between fear and Bitcoin before and after COVID-19, considering the changing dynamics with the outbreak. Thus, we can investigate the effect of the pandemic on the Bitcoin market, through investor psychology, since the pandemic created an unprecedented shock on financial markets.

The paper is organized as follows: Section 2 describes the data and the methodology. Section 3 presents and discusses the results. Section 4 concludes and provides policy implications.

\section{Data and methodology}

We retrieve fear sentiment data from Thomson Reuters MarketPsych Indices (TRMI). Bitcoin price and total transaction volume ${ }^{3}$ in its Blockchain in terms of US dollars, and daily volatility ${ }^{4}$ of Bitcoin return are obtained from coinmetrics.io for the period between January $1^{\text {st }}$, 2019 and January $31^{\text {th }}, 2021$. We denote the subperiods as pre- and post-COVID19 considering January 13th, 2020, when first Covid-19 confirmed case was reported outside China. With the pandemic, fear sentiment increased sharply to 0.012 by mid-March, which is unprecedentedly high (see Fig. 1) considering its mean and standard deviation (see Table 1).

[Figure 1 is about here]

[Table 1 is about here]

TRMI data is unique in capturing market sentiment in multiple ways. First, it is based on advanced linguistic machine learning techniques accounting for variation in sources and correlations among words. Contrary to the most of the methods used in the sentiment literature TRMI is sensitive to grammatical structures. Second, the sentiment data is highly dimensional including more than fifty sentiments and topics. Third, it has a very broad range of coverage compared to other sentiment data used in the literature. Fourth, TRMI is updated minutely and

\footnotetext{
${ }^{3}$ The sum USD value of all native units transferred (i.e., the aggregate size in USD of all transfers) that day.

${ }^{4}$ Computed as the standard deviation of the daily natural log returns over 30 days
} 
includes tens of thousands of social media and news sources (Peterson 2013; Audrino and Tetereva 2019; Griffith et al. 2020). Fifth, TRMI releases different types of sentiment data specific to each cryptocurrency.

Peterson (2016) explains how TRMIs are constructed as follows. A TRMI is formed by a combination of variables (Vars). Initially, the absolute values of all TRMI-contributing Vars are determined by the algorithm, for all asset components, over the past 24 hours. Next, "Buzz" is calculated which is the summation of these absolute values for all components. "Buzz" index is also published along with TRMIs of each asset. Namely, let $V$ be the set of all Vars underlying any TRMI of the asset class, where $a$ denotes an asset, and $C(a)$ is the set of all components of $a$. Then, Buzz is defined as follows:

$$
\operatorname{Buzz}(a)=\sum_{c \in C(a), v \in V}\left|\operatorname{Var}_{c, v}\right|
$$

Having the Buzz, a TRMI is computed as the ratio of the sum of all Vars related to a specific asset to the Buzz. $V(t)$ is defined as the set of all Vars relevant to a particular TRMI. After that, a binary function is introduced to determine whether a $\operatorname{Var} v \in V(t)$ is additive or subtractive:

$$
I(t, v)=\left\{\begin{array}{r}
+1 \text { if additive } \\
-1 \text { if subtractive }
\end{array}\right.
$$

Finally, $\mathrm{TRMI}_{\mathrm{t}}$ of an asset $a$ is computed as follows:

$$
\operatorname{TRMI}_{t}(a)=\frac{\sum_{c \in C(a), v \in V(t)}\left(I(t, v) \times \operatorname{PyschVar}_{v}(c)\right)}{\operatorname{Buzz}(\text { Asset })}
$$

In this study, we employ Bitcoin specific "fear" index as the PyschVar which measures the fear and anxiety and takes values between 0 and 1 (Peterson 2016).

We employ bivariate vector autoregressive (VAR) models given below with lag-length $\mathrm{k}$, to investigate the dynamics between Bitcoin variables and fear sentiment:

$$
\text { Model 1: } Y_{t}=c+\sum_{j=1}^{k} \beta_{j} Y_{t-j}+\epsilon_{t}
$$


where $Y_{t}=[\text { Return, Fear }]^{\prime}$ is a $2 x 1$ vector of endogenous variables, c is a vector of constants and $\epsilon_{t}$ is a vector of error terms. Model 1 captures the relationship between Bitcoin return and fear sentiment.

$$
\text { Model 2: } X_{t}=c+\sum_{j=1}^{k} \beta_{j} X_{t-j}+\epsilon_{t}
$$

where $X_{t}=[\text { Transaction, Fear }]^{\prime}$ is a $2 x 1$ vector of endogenous variables, c is a vector of constants and $\epsilon_{t}$ is a vector of error terms. Model 2 captures the relationship between Bitcoin transaction value and fear sentiment.

$$
\text { Model 3: } Z_{t}=c+\sum_{j=1}^{k} \beta_{j} Z_{t-j}+\epsilon_{t}
$$

where $Z_{t}=$ [Volatility, Fear $]^{\prime}$ is a $2 x 1$ vector of endogenous variables, $\mathrm{c}$ is a vector of constants and $\epsilon_{t}$ is a vector of error terms. Model 3 captures the relationship between Bitcoin volatility and fear sentiment.

We determine the lag-length ${ }^{5}$ using HQ Information Criteria (HQIC) criteria and check the stationarity of the variables by performing augmented Dickey-Fuller (ADF) and Phillips-Perron unit root tests with and without trends. Diagnostic tests suggest that fear, return, 30-day volatility and Log-transaction volume are stationary at their levels (Table 2).

[Table 2 is about here]

\section{Empirical results}

In order to capture dynamic relationship between variables we plot impulse response functions (IRF). ${ }^{6}$ Fig. 2, 3 and 4 display the orthogonalized impulse response functions (OIRF) of Bitcoin return, transaction volume and Bitcoin volatility respectively to one-unit standard

\footnotetext{
${ }^{5}$ The empirical results and IRFs are generated also with different lag-lengths based on other information criteria such as AIC and BIC. We find qualitatively similar results.

${ }^{6}$ See Appendix for the VAR estimation results of both subsamples.
} 
deviation shock on fear, based on the estimated bivariate VAR models. The confidence intervals are for 1 standard error confidence intervals.

Figure 2 shows the IRF for Bitcoin return (Model 1). For the pre-COVID period, the response of return is negative to an increase in fear sentiment and dies out quickly in 6 periods (days). However, after COVID-19, even the response is again negative in the initial periods, later it fluctuates, and the shock persists much longer (more than 15 periods) compared to pre-COVID. Besides, the initial response of return to a fear shock is bigger in magnitude for post-COVID compared to pre-COVID. These results imply that due to the excessive uncertainty caused by the COVID-19 outbreak, an increase in fear negatively affects the Bitcoin returns more persistently. With an increasing fear, investors become more pessimistic which increases the selling pressure (Baker and Wurgler 2006; Chen et al. 2020). The reaction of the Bitcoin fluctuates as fear sentiment leads to return reversals after COVID-19 (Tetlock 2007; Da et al. 2015). This result also implies that Bitcoin prices become exceptionally volatile with coronavirus outbreak. Investors became more sensitive to news after the outbreak. The granger causality test results further support our findings. Fear granger causes Bitcoin return in the postCOVID period more significantly (Table 3).

[Figure 2 is about here]

[Table 3 is about here]

Fig. 3 displays the response of transaction volume based on Model 2. During the pre-COVID period, a positive shock (an increase) in fear decreases transaction volume and the shock starts to die out smoothly after 50 periods. On the other hand, for the post-COVID period, an increase in fear results in more fluctuations in transaction volume even though the initial and cumulative effects are both negative. Interestingly after a few periods, transaction volume increases but reduces later and continues fluctuating 
[Figure 3 is about here]

longer. Due to extreme uncertainty caused by the COVID-19 pandemic, investors may trade more aggressively in the initial phases of the shock. However, in the end, due to increasing-bid ask prices, fear probably decreases transaction (Tetlock 2007).

Fig. 4 shows the response of volatility based on Model 3. During the pre-COVID period, an increase in fear decreases the volatility. Conversely, increasing fear has a sharp increasing effect on volatility after COVID-19. The effect is larger in magnitude and is more permanent for the post-COVID period. The increasing severity of the pandemic presumably drives investors to become more uncertain. This may lead to an increase in bid-ask spread and volatility (Lerner and Keltner 2001).

[Figure 4 is about here]

\section{Conclusions}

We investigate the relationship between Bitcoin-specific fear sentiment and Bitcoin's return, volatility and transaction volume considering the COVID-19 pandemic driven crisis. The results show that the relationship between fear and our bitcoin variables become more volatile while the shocks have more persistent effects after the COVID-19 outbreak. For conventional currencies, governments, regulators and central banks intervene in the market to stabilize their economies when faced with a crisis like the COVID-19 outbreak. However, the Bitcoin market in nature came out as a reaction to these policies. In this sense, we are convinced that our results in this paper have more far-reaching implications for other markets regulated by the states. Bitcoin provides a natural benchmark to understand how fear sentiment drives and impacts the markets isolated from any interventions. Focusing on Bitcoin-as a decentralized and unregulated market-gives us clues about how the market would have behaved in the absence of 
policy responses and trust provided by any central authority. Hence, our results show that in the absence of regulatory frameworks, market dynamics are likely to be more volatile, and the fear sentiment has more persistent impacts. This implies that smart regulation and timely interventions in the markets, such as monetary and fiscal policy responses conducted during the early stage of the outbreak, are relevant and may mitigate the sentiment driven extreme volatility in the markets. Also, considering the expectation management role of central banks, the timely response may help investors to gain confidence in markets. We also highlight the importance of using micro, asset-specific sentiment measures to capture market dynamics better. 


\section{References}

Aloosh, A. and Ouzan, S. (2020). "The psychology of cryptocurrency prices", Finance Research Letters, 33, 101192.

Audrino, F. and Tetereva, A. (2019). "Sentiment spillover effects for US and European companies", Journal of Banking \& Finance, 106, 542-567.

Aysan, A. F., Demir, E., Gozgor, G. and Lau, C. K. M. (2019). "Effects of the geopolitical risks on Bitcoin returns and volatility". Research in International Business and Finance, 47, 511 518.

Aysan, A. F. \& Bergigui, F. (2020). Blockchain Paths in Rebooting the Global Response to the Sustainable Development Goals after COVID-19. Preprints, 1-29, [online] Available at: doi:10.20944/preprints202010.0074.v1. [Accessed at: 19 August 2021].

Aysan, A. F., Bergigui, F. \& Disli, M., (2021a). Using Blockchain-Enabled Solutions as SDG Accelerators in the International Development Space, Multidisciplinary Digital Publishing Institute (13), 7, pp. 1-24. https://doi.org/10.3390/su13074025.

Aysan, A. F., Bergigui, F., \& Disli, M. (2021b). Blockchain -Based Solutions in Achieving SDGs after COVID-19. Journal of Open Innovation: Technology, Market and Complexity, 7 $1-16$. https://doi.org/10.3390/joitmc7020151.

Aysan, A. F., Demirtaş, H. B. \& Saraç, M., (2021). The Ascent of Bitcoin: Bibliometric Analysis of Bitcoin Research, Preprints, (14), 9, pp. 1-28, [online] Available at: doi:10.20944/preprints202108.0555.v1, [Accessed at: 31 August 2021].

Aysan, A. F., Disli, M., Nagayev, R., Rizkiah, S. K. \& Salim, K. (2021). In search of safe haven assets during COVID-19 pandemic: An empirical analysis of different investor types. Research in International Business and Finance, 58, https://doi.org/10.1016/j.ribaf.2021.101461.

Aysan, A. F., Khan, A. I. \& Topuz, H., (2021). Bitcoin and altcoins price dependency: 
Resilience and portfolio allocation in COVID-19 outbreak. Risks (9), 74, pp. 1-13. https://doi.org/10.3390/risks9040074.

Aysan, A. F., Khan, A. I., Topuz, H., \& Tunal1, A. S., (2021). Survival of the fittest: A natural experiment from crypto exchanges, World Scientific Publishing Company, pp. 1-20. https://doi.org/10.1142/S0217590821470020.

Aysan, A. F., Sadriu, B. \& Topuz, H., (2020). Blockchain Futures In Cryptocurrencies, Trade and Finance: A Preliminary Assessment, Buletin Ekonomi Moneter Dan Perbankan (23), 4, pp. 525-542. https://doi.org/10.21098/bemp.v23i4.1240.

Baker, M. and Wurgler, J. (2006). "Investor sentiment and the cross-section of stock returns", The Journal of Finance, 61(4), 1645-1680.

Bariviera, A. F., Basgall, M. J., Hasperué, W., \& Naiouf, M. (2017). Some stylized facts of the Bitcoin market. Physica A: Statistical Mechanics and its Applications, 484, 82-90.

Baur, D. G., Hong, K., \& Lee, A. D. (2018). Bitcoin: Medium of exchange or speculative assets?. Journal of International Financial Markets, Institutions and Money, 54, 177-189.

Bouri, E., Molnár, P., Azzi, G., Roubaud, D. and Hagfors, L. I. (2017). “On the hedge and safe haven properties of Bitcoin: Is it really more than a diversifier?", Finance Research Letters, 20, 192-198.

Bukovina, J. and Marticek, M. (2016). "Sentiment and bitcoin volatility”, MENDELU Working Papers in Business and Economics, 2016-58, Mendel University.

Chaim, P. and Laurini, M. P. (2019). “Is Bitcoin a bubble?”, Physica A: Statistical Mechanics and its Applications", 517, 222-232.

Cheah, E. T., \& Fry, J. (2015). Speculative bubbles in Bitcoin markets? An empirical investigation into the fundamental value of Bitcoin. Economics letters, 130, 32-36.

Chen, C., Liu, L. and Zhao, N. (2020). "Fear sentiment, uncertainty, and bitcoin price dynamics: The case of COVID-19”, Emerging Markets Finance and Trade, 56(10), 2298-2309. 
Conlon, T. and McGee, R. (2020). "Safe haven or risky hazard? Bitcoin during the COVID-19 bear market", Finance Research Letters, 35, 101607.

Corbet, S., Meegan, A., Larkin, C., Lucey, B., \& Yarovaya, L. (2018). Exploring the dynamic relationships between cryptocurrencies and other financial assets. Economics Letters, 165, $28-34$.

Da, Z., Engelberg, J. and Gao, P. (2015). “The sum of all FEARS investor sentiment and asset prices", The Review of Financial Studies, 28(1), 1-32.

Dahir, A. M., Mahat, F., Noordin, B. A. A. and Ab Razak, N. H. (2019). "Dynamic connectedness between Bitcoin and equity market information across BRICS countries: Evidence from TVP-VAR connectedness approach”, International Journal of Managerial Finance, Vol. 16 No. 3, pp. 357-371.

Demir, E., Bilgin, M. H., Karabulut, G. and Doker, A. C. 2020). "The relationship between cryptocurrencies and COVID-19 pandemic", Eurasian Economic Review, 10(3), 349-360.

Dyhrberg, A. H. (2016). "Bitcoin, gold and the dollar-A GARCH volatility analysis", Finance Research Letters, 16, 85-92.

Geuder, J., Kinateder, H., Wagner, N. (2019). Cryptocurrencies as financial Bubbles: The Case of Bitcoin, Finance Research Letters 31: 179-184.

Griffith, J., Najand, M. and Shen, J. (2020). "Emotions in the stock market", Journal of Behavioral Finance, 21(1), 42-56.

Guesmi, K., Saadi, S., Abid, I. and Ftiti, Z. (2019). "Portfolio diversification with virtual currency: Evidence from bitcoin”, International Review of Financial Analysis, 63, 431-437.

Kalyvas, A., Papakyriakou, P., Sakkas, A. and Urquhart, A. (2020). "What drives Bitcoin's price crash risk?", Economics Letters, 191, 108777.

Kaminski, J. (2014). "Nowcasting the bitcoin market with twitter signals", arXiv preprint arXiv:1406.7577. 
Karalevicius, V., Degrande, N. and De Weerdt, J. (2018). “Using sentiment analysis to predict interday Bitcoin price movements", The Journal of Risk Finance, 19(1), 56-75.

Kristoufek, L. (2019). "Is the Bitcoin price dynamics economically reasonable? Evidence from fundamental laws”, Physica A: Statistical Mechanics and its Applications, 536, 120873.

Lerner, J. S. and Keltner, D. (2001). "Fear, anger, and risk”, Journal of Personality and Social Psychology, 81(1), 146.

Oad Rajput, S. K., Soomro, I. A. and Soomro, N. A. (2020). "Bitcoin Sentiment Index, Bitcoin Performance and US Dollar Exchange Rate", Journal of Behavioral Finance, DOI: $10.1080 / 15427560.2020 .1864735$.

Peterson, R.L. (2013). “Thomson Reuters MarketPsych Indices (TRMI) white paper, inside the mind of the market", TRMI White Paper.

Peterson, R.L. (2016). Trading on sentiment: The power of minds over markets, John Wiley \& Sons, Inc., Hoboken, NJ.

Poyser, O. (2019). “Exploring the dynamics of Bitcoin's price: a Bayesian structural time series approach”, Eurasian Economic Review, 9(1), 29-60.

Sahoo, P. K., Sethi, D. and Acharya, D. (2019). "Is bitcoin a near stock? Linear and non-linear causal evidence from a price-volume relationship", International Journal of Managerial Finance, Vol. 15 No. 4, pp. 533-545

Shahzad, S. J. H., Bouri, E., Roubaud, D., Kristoufek, L. and Lucey, B. (2019). “Is Bitcoin a better safe-haven investment than gold and commodities?", International Review of Financial Analysis, 63, 322-330.

Shen, D., Urquhart, A. and Wang, P. (2019). "Does twitter predict Bitcoin?", Economics Letters, 174, 118-122.

Tetlock, P. C. (2007). "Giving content to investor sentiment: The role of media in the stock market”, The Journal of Finance, 62(3), 1139-1168. 
Vandezande, N. (2017). Virtual currencies under EU anti-money laundering law. Computer Law \& Security Review, 33(3), 341-353.

Zeng, T., Yang, M., \& Shen, Y. (2020). Fancy Bitcoin and conventional financial assets: Measuring market integration based on connectedness networks. Economic Modelling, 90, 209-220. 


\section{APPENDIX}

Table A.1. VAR estimation results for Model 1

\begin{tabular}{lcccc}
\hline & \multicolumn{2}{c}{ Pre-COVID } & \multicolumn{2}{c}{ Post-COVID } \\
\hline & Return $_{\mathrm{t}}$ & Fear $_{\mathrm{t}}$ & Return $_{\mathrm{t}}$ & Fear $_{\mathrm{t}}$ \\
$\mathrm{R}_{\mathrm{t}-1}$ & -0.0736 & $-0.0017^{*}$ & $-0.1112^{* *}$ & $-0.0045^{* * *}$ \\
$\mathrm{R}_{\mathrm{t}-2}$ & & & 0.0475 & -0.0010 \\
$\mathrm{R}_{\mathrm{t}-3}$ & & -0.7550 & -0.0017 \\
$\mathrm{R}_{\mathrm{t}-4}$ & & $0.1178^{* *}$ & 0.0008 \\
$\mathrm{R}_{\mathrm{t}-5}$ & & & 0.0196 & $0.0023^{* *}$ \\
\hline $\mathrm{F}_{\mathrm{t}-1}$ & $-3.9695^{*}$ & $0.4504 * * *$ & -1.4986 & $0.4624^{* * *}$ \\
$\mathrm{~F}_{\mathrm{t}-2}$ & & & 0.1898 & $0.1443^{* *}$ \\
$\mathrm{~F}_{\mathrm{t}-3}$ & & -2.2520 & 0.0832 \\
$\mathrm{~F}_{\mathrm{t}-4}$ & & & $6.8282^{* *}$ & -0.0465 \\
$\mathrm{~F}_{\mathrm{t}-5}$ & & & -1.7410 & $0.2041 * * *$ \\
\hline
\end{tabular}

Notes: pre- and post- Covid periods cover the dates from 1 January, 2019 to 14 March, 2020 and from 15 March, 2020 to 31 January, 2021, respectively.

Table A.2. VAR estimation results for Model 2

\begin{tabular}{|c|c|c|c|c|}
\hline & \multicolumn{2}{|c|}{ Pre-COVID } & \multicolumn{2}{|c|}{ Post-COVID } \\
\hline & Transaction $_{\mathrm{t}}$ & Fear ${ }_{t}$ & Transaction $_{\mathrm{t}}$ & Fear $_{t}$ \\
\hline $\mathrm{T}_{\mathrm{t}-1}$ & $0.4918^{* * *}$ & 0.0000 & $0.4227 * * *$ & 0.0002 \\
\hline $\mathrm{T}_{\mathrm{t}-2}$ & 0.0860 & 0.0002 & 0.0338 & -0.0000 \\
\hline $\mathrm{T}_{\mathrm{t}-3}$ & 0.0145 & 0.0002 & $0.1564 * * *$ & 0.0001 \\
\hline $\mathrm{T}_{\mathrm{t}-4}$ & 0.0690 & -0.0001 & -0.0004 & -0.0000 \\
\hline $\mathrm{T}_{\mathrm{t}-5}$ & -0.0491 & -0.0001 & -0.0722 & -0.0000 \\
\hline $\mathrm{T}_{\mathrm{t}-6}$ & $0.1813^{* * *}$ & 0.0000 & $0.2217^{* * *}$ & -0.0000 \\
\hline $\mathrm{T}_{\mathrm{t}-7}$ & $0.3506^{* * *}$ & 0.0001 & $0.4598 * * *$ & 0.0001 \\
\hline $\mathrm{T}_{\mathrm{t}-8}$ & -0.0653 & 0.0001 & -0.020 & $-0.0003 *$ \\
\hline $\mathrm{T}_{\mathrm{t}-9}$ & $-0.1596^{* * *}$ & -0.0002 & $-0.2095 * * *$ & 0.0001 \\
\hline $\mathrm{F}_{\mathrm{t}-1}$ & -9.3317 & $0.4291 * * *$ & -11.735 & $0.5180 * * *$ \\
\hline $\mathrm{F}_{\mathrm{t}-2}$ & -25.5661 & 0.0322 & -9.2434 & $0.1315^{* *}$ \\
\hline $\mathrm{F}_{\mathrm{t}-3}$ & -2.4945 & 0.0253 & 23.921 & 0.0692 \\
\hline $\mathrm{F}_{\mathrm{t}-4}$ & 6.7491 & -0.0172 & -1.9842 & -0.0763 \\
\hline $\mathrm{F}_{\mathrm{t}-5}$ & $-56.1848 * * *$ & 0.0139 & $-29.607^{* *}$ & $0.1874 * * *$ \\
\hline $\mathrm{F}_{\mathrm{t}-6}$ & -21.2933 & -0.0051 & $-29.6931 * *$ & -0.0283 \\
\hline $\mathrm{F}_{\mathrm{t}-7}$ & 34.3180 & -0.0030 & 18.8800 & -0.0291 \\
\hline $\mathrm{F}_{\mathrm{t}-8}$ & -2.5259 & 0.0731 & 21.7719 & 0.0351 \\
\hline$F_{t-9}$ & $-42.1709 * *$ & 0.0063 & 14.0921 & 0.0233 \\
\hline
\end{tabular}

Notes: pre- and post-Covid periods cover the dates from 1 January, 2019 to 14 March, 2020 and from 15 March, 2020 to 31 January, 2021, respectively. 
Table A.3. VAR estimation results for Model 3

\begin{tabular}{ccccc}
\hline & \multicolumn{2}{c}{ Pre-COVID } & \multicolumn{2}{c}{ Post-COVID } \\
\hline $\mathrm{V}_{\mathrm{t}-1}$ & Volatility & Fear $_{\mathrm{t}}$ & Volatility $_{\mathrm{t}}$ & Fear $_{\mathrm{t}}$ \\
$\mathrm{V}_{\mathrm{t}-2}$ & $1.0048^{* * *}$ & -0.0084 & $1.0254^{* * *}$ & $0.0314514^{* * *}$ \\
$\mathrm{~V}_{\mathrm{t}-3}$ & 0.1051 & 0.0195 & -0.0591 & -0.0232347 \\
$\mathrm{~V}_{\mathrm{t}-4}$ & $-0.1340^{* * *}$ & -0.0085 & -0.0527 & 0.024437 \\
$\mathrm{~F}_{\mathrm{t}-1}$ & & & 0.0445 & $-0.0306693^{* * *}$ \\
$\mathrm{~F}_{\mathrm{t}-2}$ & 0.1488 & $0.4349 * * *$ & 0.1639 & $0.4908896^{* * *}$ \\
$\mathrm{~F}_{\mathrm{t}-3}$ & -0.0757 & 0.0338 & 0.080 & $0.1413264 * *$ \\
$\mathrm{~F}_{\mathrm{t}-4}$ & -0.2457 & 0.0140 & $1.000^{* * *}$ & $0.095465^{*}$ \\
\hline
\end{tabular}

Notes: pre-and post-Covid periods cover the dates from 1 January, 2019 to 14 March, 2020 and from 15 March, 2020 to 31 January, 2021, respectively. 

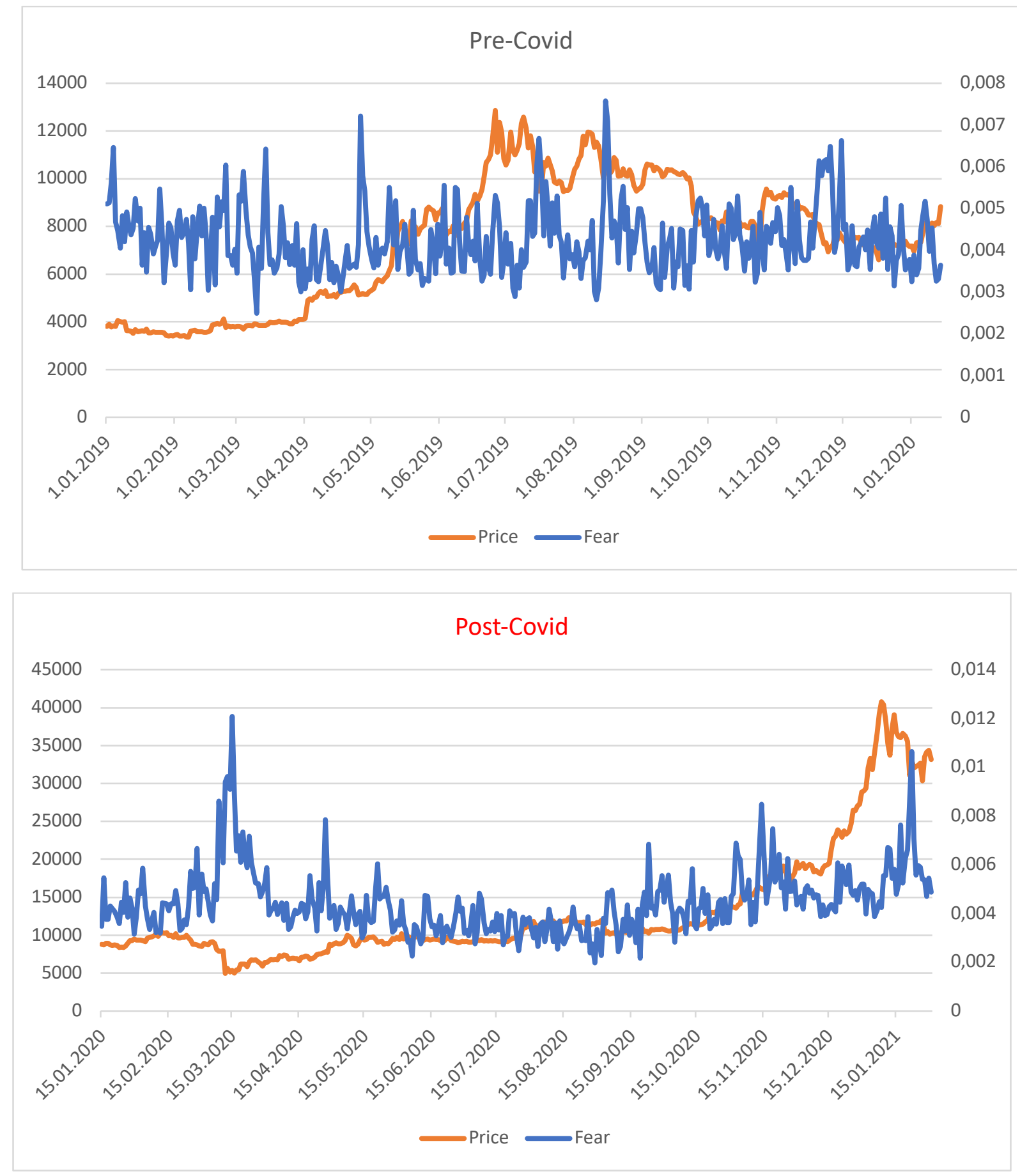

Fig. 1. Fear and BTC price (USD). 
Table 1.a. Summary statistics for pre-Covid period

\begin{tabular}{lcccccc}
\hline & Mean & SD & Min & Max & Skewness & Kurtosis \\
\hline Fear & 0.0042 & 0.0008 & 0.0025 & 0.0075 & 0.90931 & 4.2465 \\
Return & 0.0022 & 0.0365 & -0.1465 & 0.1697 & 0.3302 & 6.9914 \\
Log-Transaction Volume & 23.4472 & 0.5116 & 22.1874 & 24.5322 & -0.6643 & 2.8457 \\
30-day Return Volatility & 0.0353 & 0.0116 & 0.0119 & 0.0696 & 0.8123 & 3.4139 \\
\hline
\end{tabular}

Notes: pre-Covid covers the period from 1 January, 2019 to 14 March, 2020.

Table 1.b. Summary statistics for post-Covid period

\begin{tabular}{lcccccc}
\hline & Mean & SD & Min & Max & Skewness & Kurtosis \\
\hline Fear & 0.0041 & 0.0013 & 0.0019 & 0.0121 & 2.2333 & 10.850 \\
Return & 0.0007 & 0.0442 & -0.4705 & 0.1401 & -4.411 & 51.889 \\
Log-Transaction Volume & 24.1253 & 0.3812 & 23.229 & 25.0294 & -0.3255 & 2.3615 \\
30-day Return Volatility & 0.0376 & 0.0242 & 0.0117 & 0.1055 & 2.0116 & 5.7668 \\
\hline
\end{tabular}

Notes: post-Covid covers the period from 15 March, 2019 to 31 January, 2021.

Table 2. Unit root test results

\begin{tabular}{lcc|cc}
\hline & \multicolumn{2}{c|}{ Pre-Covid } & \multicolumn{2}{c}{ Post-Covid } \\
\hline Variables & ADF & Philips-Perron & ADF & Philips-Perron \\
\hline Fear Sentiment & $-11.788^{* * *}$ & $-11.840^{* * *}$ & $-6.409^{* * *}$ & $-6.143^{* * *}$ \\
Bitcoin Return & $-20.671 * * *$ & $-20.651^{* * *}$ & $-19.701^{* * *}$ & $-19.476^{* * *}$ \\
30-day Volatility & $-2.079 *$ & $-2.359^{*}$ & -1.621 & -1.786 \\
Log-transaction volume & $-3.494 * * *$ & $-2.804 *$ & $-4.061 * * *$ & $-3.400^{* *}$ \\
\hline
\end{tabular}

*** Indicates significance at $1 \%$. ** Indicates significance at $5 \%$. * Indicates significance at $10 \%$.

Notes: pre-and post-Covid periods cover the dates from 1 January, 2019 to 14 March, 2020 and from 15 March, 2020 to 31 January, 2021, respectively. 

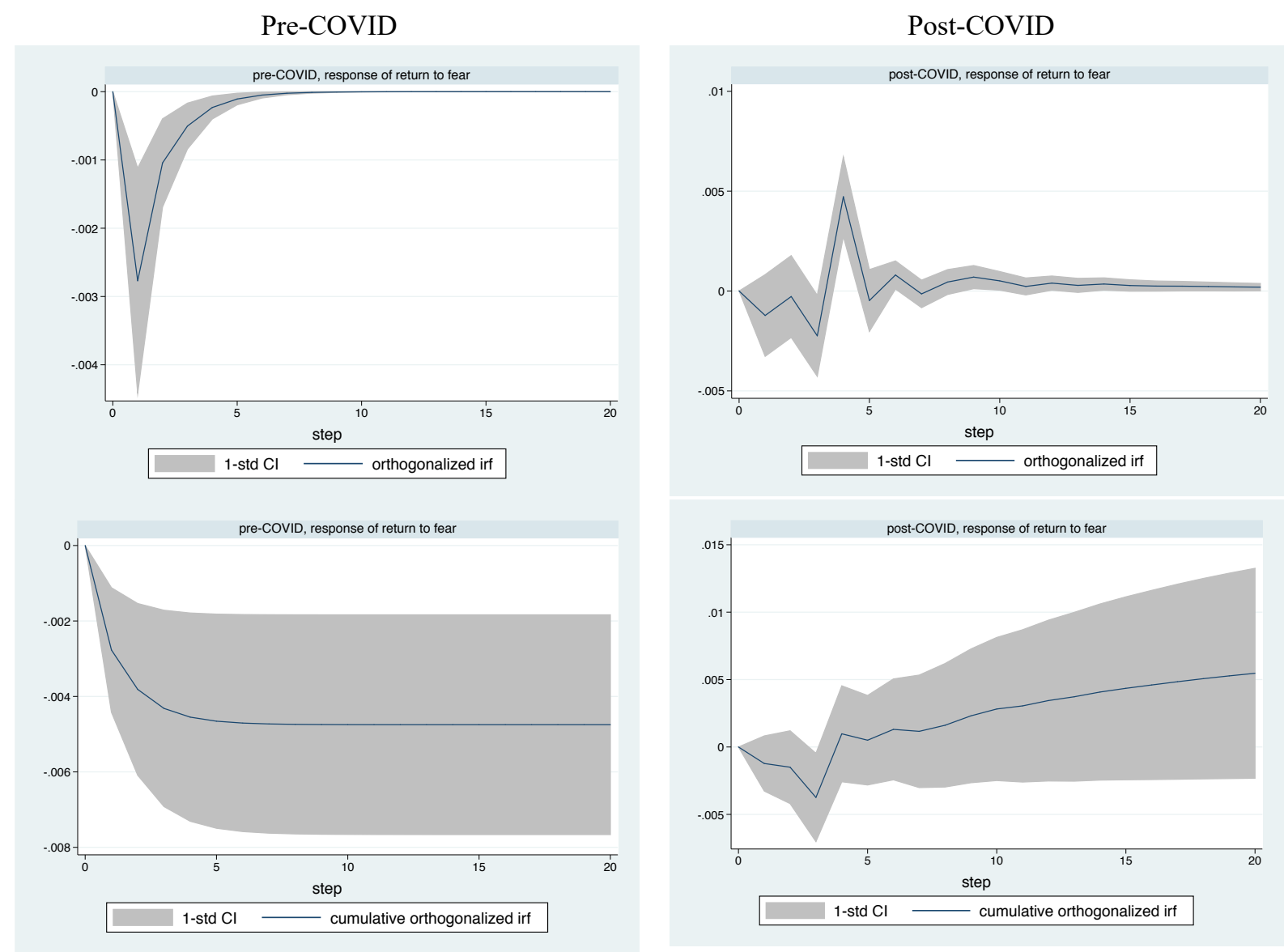

Fig. 2. Orthogonalized and cumulative IRFs for pre- and post-COVID periods of Bitcoin return (Model 1). Notes: This figure show the response of BTC return to a shock in fear having 1-standard deviation confidence intervals. 
Table 3. Granger causality Wald test results.

\begin{tabular}{llll}
\hline Pre-COVID & & Post-COVID & \\
\hline Fear does not granger cause Return & $2.7952^{*}$ & Fear does not granger cause Return & $16.899^{* * *}$ \\
$\begin{array}{l}\text { Fear does not granger cause transaction } \\
\text { volume }\end{array}$ & $24.383^{* * *}$ & $\begin{array}{l}\text { Fear does not granger cause transaction } \\
\text { volume }\end{array}$ & $20.624 * * *$ \\
Fear does not granger cause volatility & 3.3468 & Fear does not granger cause volatility & $33.03 * * *$ \\
\hline$* * *$ Indicates significance at $1 \% *$ Indicates & &
\end{tabular}

*** Indicates significance at $1 \%$ * Indicates significance at $10 \%$

Notes: pre- and post-Covid periods cover the dates from 1 January, 2019 to 14 March, 2020 and from 15 March, 2020 to 31 January, 2021, respectively. 
Pre-COVID
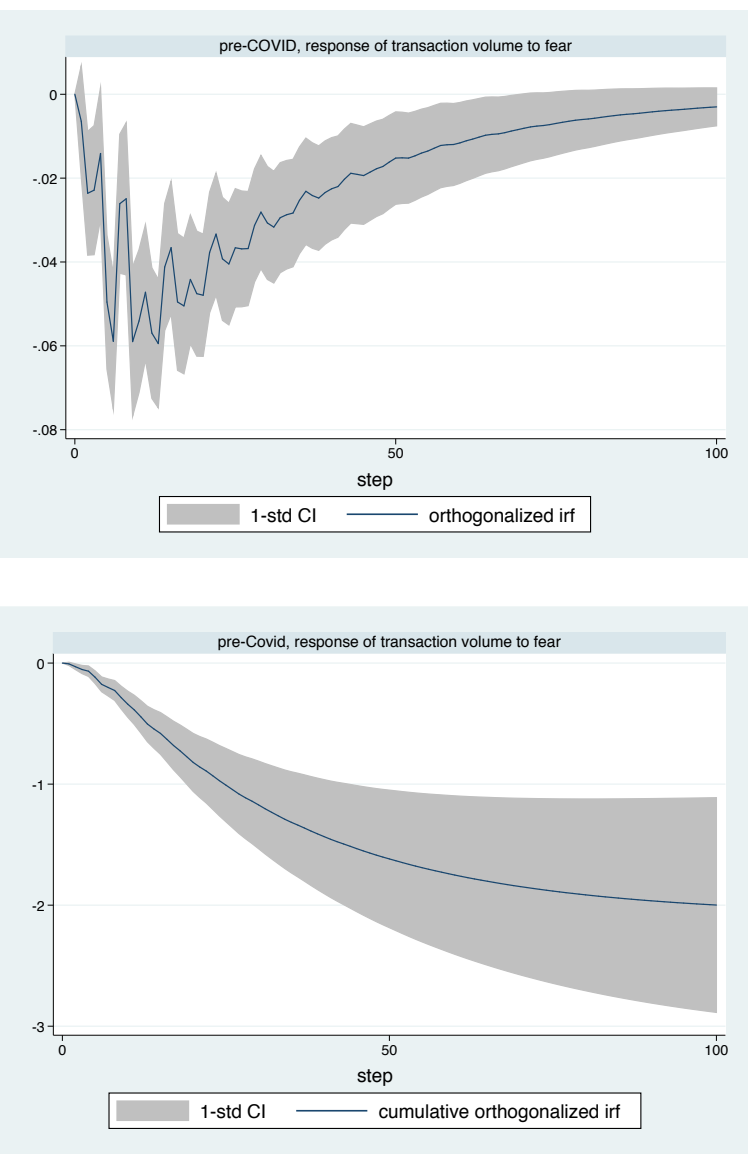

Post-COVID

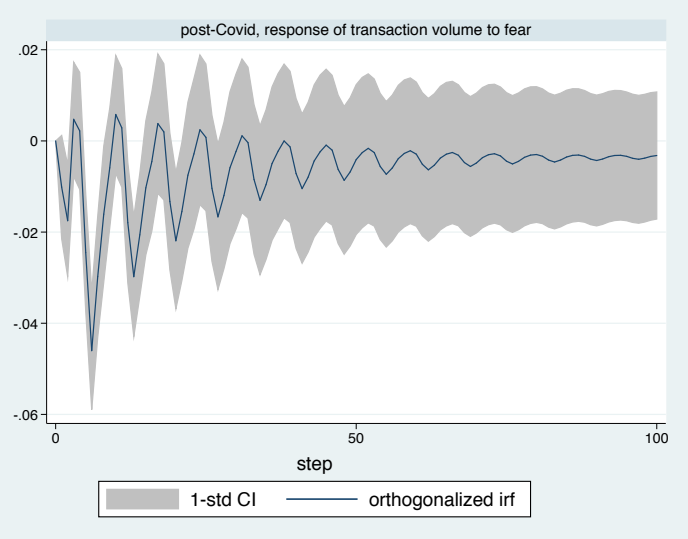

post-COVID, response of transaction volume to fear

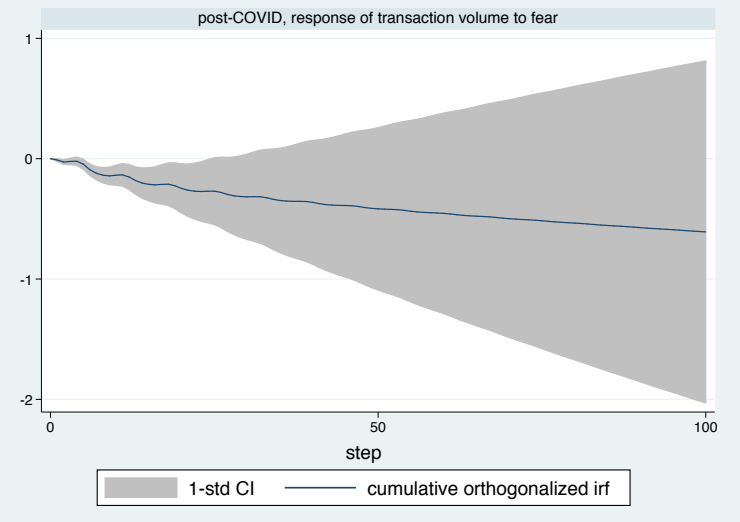

Fig. 3. Orthogonalized and cumulative IRFs for pre- and post-COVID periods of transaction volume to a shock in fear. 


\section{Pre-COVID}

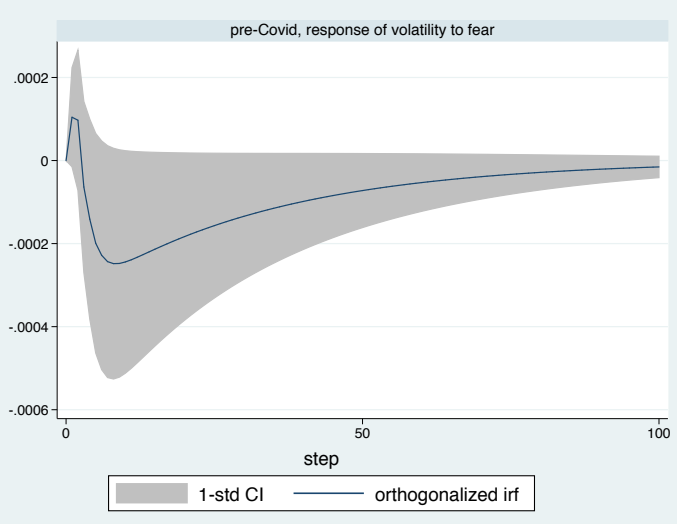

pre-Covid, response of volatility to fear

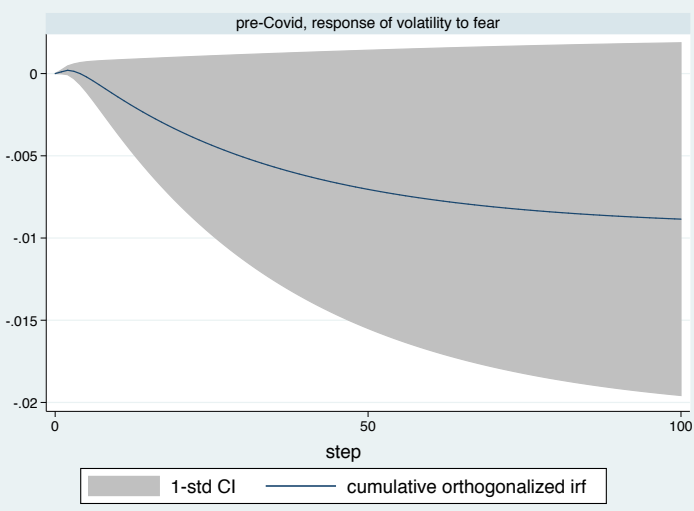

Post-COVID

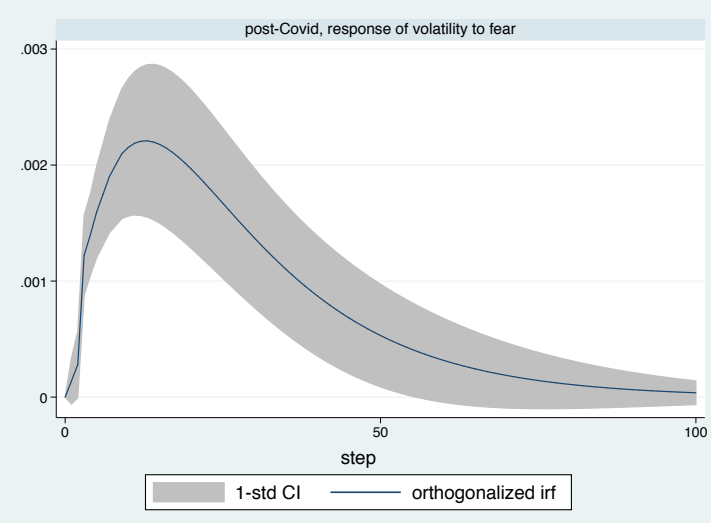

post-Covid, response of volatility to fear

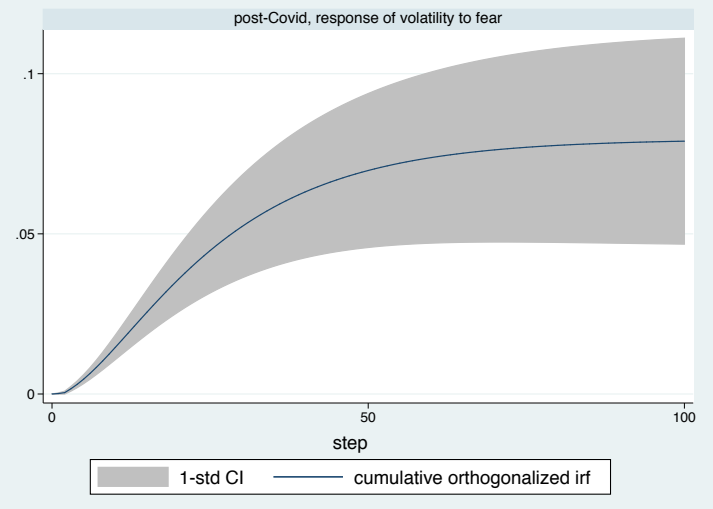

Fig. 4. Orthogonalized and cumulative IRFs for pre- and post-COVID periods of volatility to a shock in fear. 